Ciencia y Educación, Vol. 6, No. 1, enero-abril, 2022

ISSN (impreso): 2613-8794 • ISSN (en línea): 2613-8808

DOI: https://doi.org/10.22206/cyed.2022.v6i1.pp7-26

\title{
Innovación disruptiva y Nueva Identidad Docente Modelo AIE-UCA de formación por aptitudes
}

\author{
Disruptive Innovation and New Teaching Identity AIE-UCA: \\ Training teachers by abilities
}

Andrés Peregallia ORCID: 0000-0002-0057-7665

Hernán Rodriguez ${ }^{\mathrm{b}}$ ORCID: 0000-0001-7745-9301

Recibido: 13/04/2021 • Aprobado: 20/09/2021

Cómo citar: Peregalli, A., \& Rodríguez, H. Innovación disruptiva y Nueva Identidad Docente Modelo AIE-UCA de formación por aptitudes. Ciencia y Educación, 6(1), 7-26. https://doi.org/10.22206/cyed.2022.v6i1.pp7-26

Resumen

La profesionalización docente requiere de una transformación innovadora en la formación inicial que reformule la identidad y supere una formación academicista propiciando un aprendizaje multidimensional y situado. Este artículo describe los resultados del modelo innovador de formación docente inicial AIE-UCA (Aprendizaje Inclusivo y Efectivo-Universidad Católica Argentina), desarrollado para superar las limitaciones de los modelos tradicionales. A tales efectos desarrolla el concepto de innovación, las condiciones institucionales que posibilitan su realización y las características que conforman el desarrollo de la profesionalidad (nueva identidad). Se realiza un análisis ex post facto mediante una metodología mixta sustentada en gran medida en el análisis cualitativo de contenido de desempeños de estudiantes durante los primeros cuatro años de despliegue de la experiencia. Los resultados evidencian una formación inicial innovadora en la cual los futuros educadores desarrollan conscientemente capacidades profesionales que integran conocimientos disciplinares, experiencia práctica y posicionamiento ético-político. También aportan evidencias sobre las transformaciones organizacionales que

\begin{abstract}
Teacher professionalization requires, among other things, an innovative transformation in initial training that reformulates the identity and goes beyond encyclopedic education, promoting multidimensional and situated learning. This article describes the results of the innovative model of initial teacher training AIE UCA (Inclusive and Effective Learning - Argentinian Catholic University), developed in order to overcome the limitations of traditional models. To this end, it analyses the concept of innovation, the institutional conditions that make its realization possible and the characteristics that shape the development of professionalism (new identity). An ex post facto analysis was carried out using a mixed methodology based to a great extent on the qualitative content analysis of student outcomes during the first four years of deployment of the project. The results show an innovative initial training in which future educators consciously develop professional skills that integrate disciplinary knowledge, practical experience and ethical-political position. They also provide evidence on the organizational transformations that made possible an inclusive and effective innovative experience, with encouraging
\end{abstract}

\footnotetext{
a Universidad Católica Argentina, Argentina. Correo-e: andresperegalli@uca.edu.ar

a Universidad Católica Argentina, Argentina. Correo-e: hernanrodriguez@uca.edu.ar
} 
posibilitaron una experiencia innovadora inclusiva y efectiva, con indicadores alentadores de eficiencia interna y de reducción sustantiva de la brecha educativa entre los estudiantes que forman parte de la experiencia.

Palabras clave: formación inicial docente, profesionalización docente, inclusión, competencias, cognición situada, innovación.

\section{Introducción $^{\mathrm{a}}$}

Es bien conocida y ampliamente aceptada la frase que afirma que la calidad de un sistema educativo tiene como techo la calidad de sus docentes (McKinsey, 2007), pero modificar la formación docente parece ser una empresa bastante difícil. Hace ya 25 años, Hopkins señalaba, con relación a la formación docente, que los intentos de cambio son muchos, aunque con pocas (y poco sustantivas) variaciones que no van al corazón del problema (Hopkins, 1996).

Gran parte de la discusión actual sobre la docencia se refiere a cómo mejorar la calidad de su desempeño. Múltiples autores han planteado la inquietud de que para "profesionalizar" la docencia no basta con mejorar las condiciones de trabajo, ascenso y reconocimiento y/o establecer requerimientos mayores para su ejercicio, sino también proponer una formación inicial que "brinde herramientas para superar un ejercicio de la profesión consuetudinario - didáctica "por defecto" (Terigi, 2012)-, o tecnicista, y que permita un uso flexible y reflexivo del saber científico" (Rodriguez, 2021, p. 10; Perkins, 1999; Perrenoud, 2007; Muñoz et al., 2017; Reimers, 2020) El sistema de formación docente (sistema formador) es una organización compleja cuya dinámica se estructura desde un modelo clásico que se puede sintetizar, por un lado, en el Triángulo Didáctico (TD) -que hace referencia a sus tres componentes: el conocimiento que se transmite, el alumno o el proceso de aprendizaje, y el profesor o el proceso de enseñanza- y, por otro lado, en un modelo institucional específico, una gramática (Tyack \& Cuban, 2001) que responde a las características del indicators of internal efficiency and substantial reduction of the educational gap among students taking part in the experience.

Keywords: Initial teacher training, teacher professionalization, inclusion, competences, situated cognition, innovation.

TD y condiciona las reglas de la organización. Como ambos elementos están imbricados mutuamente, esta situación hace difícil cualquier desviación de la concepción ya formada de lo que es una institución educativa en general y de formación docente en particular.

Desde la perspectiva que adopta este trabajo, existe innovación solo cuando hay una redefinición estructural del TD que llega hasta la modificación de la organización (condiciones institucionales); cuando se instala una disrupción profunda que genera un cambio de paradigma (Aguerrondo, 1993; Rodríguez, 2014). La redefinición del TD supone que cada uno de sus tres elementos se resignifique desde un marco conceptual innovador. Sintéticamente, el conocimiento deja de ser entendido como "simple" para redefinirse desde la complejidad; el alumno deja de considerarse como pasivo para ser activo (constructivismo); y la función del profesor deja de entenderse como transmisión para ser facilitador de experiencias de aprendizaje, creador y recreador de cultura. Estas redefiniciones son imposibles de ser implementadas sin un cambio en los aspectos organizativos (Aguerrondo et al., 2001), en las reglas formales que estructuran la institución, por ejemplo: distribución de tiempos y espacios, reorganización curricular y cambios en las formas de designación docente (Peregalli, 2017).

Concebir el conocimiento como complejo implica comprender su carácter multidimensional y situado (Díaz Barriga, 2003), pues está integrado no solo por un discurso que da cuenta de él en forma más o menos efectiva, sino por determinadas formas de acción y valoración que funcionan en ese contexto

\footnotetext{
a Agradecemos a Inés Aguerrondo la revisión de este artículo y las valiosas sugerencias para su realización.
} 
específico (Rodríguez, 2021, 2016). "Es un saber que permite interactuar en ese contexto en base a fines y, en este sentido, puede pensarse como una capacidad" (Rodriguez, 2021, p. 44). Se supera así la distinción entre "conocimiento académico" y "conocimiento aplicado" (Aguerrondo, 2009; Vezub et al., 2019) y se concibe el aprendizaje como apropiación intrasubjetiva (Baquero, 2002) e intersubjetiva de experiencias complejas, multidimensionales y situadas (Rodriguez, 2021).

Diferentes autores señalan que el desempeño docente surge de una combinación compleja y situada de conocimientos teóricos y prácticos, actitudes y valores (Perrenoud, 2007; Muñoz et al., 2017). Los conceptos de competencia, capacidad y aptitud remiten a esta combinación compleja, aunque pueden referir a concepciones diferentes utilizándose polisémicamente y generando no pocas confusiones (Rodriguez, 2021; Pavié, 2011; Escrich Gallardo et al., 2015). En este artículo estos conceptos se utilizan indistintamente y se los comprende como el despliegue situado de un conocimiento multidimensional que integra, cuanto menos, un saber, un saber hacer y un saber ser (dimensión simbólica, práctica y ética del conocimiento). El aprendizaje en términos de desarrollo consciente de capacidades pone en el foco la construcción protagónica y situada del conocimiento. En este sentido, comprende el desarrollo de una capacidad para una situación específica. El contexto y las relaciones intersubjetivas están imbricados en el aprendizaje y son reconstruidos y apropiados por el aprendiz. El aprendizaje, en cuanto desarrollo de capacidades, se transfiere a situaciones semejantes como, en este caso, el campo profesional (Rodriguez, 2021, p. 55) Esto implica repensar la enseñanza como la estructuración multidimensional de experiencias profesionales de aprendizaje en las cuales el aprendiz asume un rol protagónico y consciente del proceso. La metacognición deviene esencial para el desarrollo consciente y creativo de las capacidades y la mayor posibilidad de transferencia (Bruer, 1995).

Desde esta perspectiva, el presente artículo analiza el modelo de formación docente inicial que lleva adelante desde 2012 el Departamento de Educación de la Pontificia Universidad Católica Argentina (UCA), denominado Aprendizaje Inclusivo y Efectivo (AIE), cuyo propósito es formar docentes profesionales. A partir de un análisis ex post facto de diseño flexible y mixto de desempeños de los estudiantes y documentos institucionales se concluye que se trata de una innovación disruptiva que responde a la necesidad de formar docentes, educadores y especialistas en cada nivel del sistema educativo con una impronta profesional, a través del desarrollo de un enfoque de enseñanza y de aprendizaje basado en aptitudes, desde una perspectiva personalista y humanista: una educación integral.

La experiencia se apoya de manera particular en el modelo que el Alverno College de Milwakee (1), EE. UU., viene desarrollando desde hace más de 40 años (Diez et al., 2010). Conocer este modelo fue un hito fundamental en este proceso ya que constituyó la demostración empírica de que cambiar la formación docente inicial es posible, pero para hacerlo es menester cambiarla, empresa no fácil. La propuesta de Alverno College no es más de lo mismo: es llevar a la práctica con mucho éxito una visión alternativa, una innovación, entendida como disrupción profunda que modifica el TD y las condiciones institucionales (organización) de la formación docente.

La segunda fuente de inspiración del modelo AIE-UCA ha sido el Marco EpC (Enseñanza para la Comprensión), desarrollado por David Perkins y su equipo a través del Proyecto Zero de la Universidad de Harvard (2), EE. UU. La noción de comprensión (como aprendizaje profundo), de desempeños (como etapas progresivas de un trayecto formativo) y de puertas de entrada al conocimiento (como vías para acceder a lo complejo) sustentan el AIE-UCA.

Una tercera fuente de inspiración, pero ya de aprendizaje y experimentación para elaborar un modelo situado en la realidad latinoamericana, fue "el saber de experiencia local”. Está constituido por todo lo aprendido en el proceso de diseño e implementación (en curso), que se fue ajustando progresivamente, respondiendo a situaciones que no siempre 
se habían previsto. Construir una nueva identidad docente implica diseñar, implementar, evaluar, ajustar y rediseñar el TD y la organización, y esto se hace (y aprende) haciendo (3).

El modelo AIE-UCA es una experiencia en movimiento, que está sucediendo, cuya primera cohorte egresó en el año 2020 (4). Las conclusiones de este artículo son primeras evidencias que deberán ser validadas en el futuro. Sin embargo, el análisis de su implementación y de sus resultados resulta pertinente y promisorio para el sistema formador docente local e internacional.

\section{Metodología}

Este artículo describe la experiencia innovadora de formación docente inicial AIE-UCA (Argentina). El diseño de investigación es mixto y flexible (Piovani, 2018). Se realiza un análisis ex post facto de diferentes corpus documentales divididos en dos grandes tipos: institucionales (organizacionales, administrativos y pedagógicos) y estudiantiles. Los documentos institucionales fueron analizados en función de las características organizacionales innovadoras de la propuesta pedagógica implementada. Además, se sistematizaron 1.000 desempeños de síntesis -trabajos finales de las unidades curriculares- de los estudiantes durante el período 2017-2020 -primeros cuatro años de implementación del modelo AIE-UCA-. Se realizó un muestreo teórico de esos desempeños buscando la mayor heterogeneidad posible: que respondieran a diferentes aptitudes, unidades curriculares, ańos y origen socioeconómico de los estudiantes. De los diversos desempeños uno de los más valiosos, a los fines de este artículo, fueron los 40 E-portfolios (6) en los que los estudiantes de cuarto ańo (2020) recogieron y sistematizaron evidencias del desarrollo de sus aptitudes profesionales durante toda su trayectoria formativa. El E-portfolio es un instrumento de monitoreo y evaluación de los aprendizajes que permite a los estudiantes reflexionar, junto con sus tutores, acerca de las fortalezas y debilidades en el desarrollo de esas aptitudes. Como la evaluación de todas las unidades curriculares se realiza sobre la base de desempeños profesionales (7), y se focaliza en algunas de esas aptitudes (consciencia y reflexividad sobre su desarrollo), es una fuente privilegiada de información para cotejar la efectividad del modelo (Aguerrondo \& Gómez Caride, 2019).

Se analizaron los desempeños desde preguntas orientadas a contrastar el carácter innovador de la experiencia y la concreción del currículo basado en aptitudes: ¿Los estudiantes disciernen el despliegue de sus aptitudes profesionales durante la práctica? ¿Pueden dar cuenta de un proceso metacognitivo para su desarrollo? ¿Evidencian estas aptitudes como uso situado, consciente y sistemático de saber profesional y de una identidad docente inclusiva y efectiva (incorporando una dimensión ética)? ¿Las evidencias dan cuenta de una redefinición del TD en los términos planteados por el modelo AIE-UCA? Estas preguntas fueron solo orientativas, dando lugar a un diseño flexible de la metodología en vista a la construcción de teoría fundamentada (Charmaz, 2013; Verd \& Lozares, 2016). De ese análisis (contenido temático) surgieron evidencias cualitativas y cuantitativas que permitieron construir siete postulados teóricos que orientan la descripción de la experiencia. Estos postulados son: 1) Aprender a aprender, 2) La reflexión y la autoevaluación conducen a la mejora permanente, 3) El conocimiento es inseparable de su aplicación/acción, 4) Saber incluir supone haber pasado por la experiencia de inclusión, 5) Formar ciudadanos del mundo para un mundo global, 6) La tecnología es una competencia transversal, 7) El vínculo formación docente inicial-formación continua retroalimenta el AIE.

\section{Resultados}

Los resultados se estructuran en tres complementarias secciones referenciadas en el marco conceptual que sustenta la investigación: una innovación disruptiva, las condiciones institucionales y el desarrollo de la profesionalidad. Cada sección evidencia el proceso de construcción y desarrollo del Modelo AIE-UCA, enfatizando en cada caso cuestiones teórico-conceptuales, político-organizacionales y de gestión, y postulados epistémicos, pedagógicos y didácticos. 


\section{Una innovación disruptiva}

Del análisis de los documentos institucionales y los desempeños de los estudiantes se revela que el modelo AIE-UCA logra estructurar experiencias multidimensionales y reflexivas de aprendizaje (didáctica disruptiva) que se transfieren al futuro desempeño docente e implican el desarrollo consciente, protagónico y reflexivo de capacidades o aptitudes profesionales. Como se expresará más adelante, las aptitudes se desarrollan, evidencian y evalúan a través de Desempeños de Comprensión (DC) (Perkins, 1999), entendidos como actividades complejas que permiten a los estudiantes construir aprendizajes profundos. En los DC la teoría enlaza con sus dimensiones prácticas y éticas, y los estudiantes, al desarrollar sus aptitudes profesionales, crean conocimiento nuevo, reconfigurando, expandiendo y aplicando lo que saben.

Para esto, la evaluación se comprende como assessment (etimológicamente "sentarse con") e implica coevaluación entre docentes y estudiantes que permita, a estos últimos, tomar conciencia y dirigir su propio proceso de aprendizaje (Aguerrondo \& Gómez Caride, 2019; Armengol-Asparó et al., 2020; Cardoner \& Ravela, 2020). Este modelo de formación docente inicial se fundamenta en la definición de cinco aptitudes de la docencia profesional (8). Las aptitudes son la expresión del actuar de una persona en su totalidad y se adquieren y fortalecen en un proceso continuo. Toda persona del campo de la educación, en cualquiera de sus roles, para ejercer su profesionalidad desarrollará cinco aptitudes:

- Conceptualización: un profesional docente conoce en profundidad y puede comprender la temática de la que se ocupa y los marcos pedagógicos que regularán su quehacer. Ese conocimiento se verá enriquecido por la interacción permanente entre lo que sabe, lo que hace y lo que es (ética).

- Diagnóstico: un profesional docente diagnostica adecuadamente la situación a modificar, sea el aprendizaje del alumno, el trabajo con sus pares o la mejora institucional, teniendo en cuenta el contexto.

- Gestión efectiva: un profesional docente maneja eficazmente los recursos, materiales e inmateriales, que organizan su propuesta de mejora del aprendizaje o de la institución; busca generar las condiciones para que esto suceda en pos de garantizar el derecho a la educación (aprender).

- Comunicación: un profesional docente utiliza múltiples vías para comunicarse: oral, escrita, con tecnologías, por el arte, en otros idiomas, etcétera; comunica lo que sabe adaptándose a la situación.

- Interacción inclusiva: un profesional organiza sus intervenciones de tal manera que todos los actores involucrados en el hecho educativo puedan incorporarse a (participar en) procesos de aprendizaje profundos, cuidando la calidad del clima de la relación interpersonal y el tipo de intervenciones que suceden en ellas.

Estas son las aptitudes profesionales cuyo desarrollo se planifica a lo largo de cuatro años, distribuyéndolas progresivamente en las respectivas unidades curriculares (y a través de ciertos niveles) para formar una nueva identidad docente.

\section{Las condiciones institucionales}

En el momento de entrar en contacto con el Alverno College, el Departamento de Educación de la UCA estaba frente a una coyuntura de necesidad de cambio y con la decisión de llevar adelante un proyecto innovador. El diagnóstico de situación dio cuenta de la necesidad de un cambio profundo, lo que facilitó el acuerdo interinstitucional. Desde 2012 a 2017 se sucedieron actividades preparatorias y de diseño y planificación de la innovación, tales como conocer en detalle el Proyecto Alverno; organizar la capacitación/reconversión del claustro docente en este nuevo modelo (para lo cual se aprovechó el desarrollo de la propuesta de EpC en Argentina); elaborar los lineamientos curriculares que contemplaran la normativa 
nacional vigente, pero que dejaran ventanas abiertas para cambios fuertes (currículum por aptitudes); y delinear una organización institucional acorde con la premisa de llevar a la práctica el principio declarado de colocar en el centro de interés los resultados del aprendizaje de los estudiantes. Se diseñó un Plan Estratégico de Desarrollo de la Innovación con objetivos, etapas, metas y productos esperados (UCA, 2018).

La nueva propuesta institucional dejó de lado el modelo clásico de la universidad jerárquica, que funciona con una conducción que toma las decisiones y con profesores que dan clase y realizan investigación, para elaborar un modelo de estructura organizativa que lleva un sello matricial en algunos aspectos pero que incorpora los principios de la nueva orga- nización estratégica y en red (Castells, 2006) y busca crear una nueva cultura institucional. El diseño de este proceso fue facilitado e incentivado desde el asesoramiento interinstitucional del Alverno College, para quienes:

La reestructuración organizativa es un componente esencial de la transformación, pero no el único. Las estructuras no son necesariamente físicas (nueva oficina, nuevo edificio) sino que comprenden tiempo, roles y responsabilidades, lo que puede llevar a la necesidad de revisar los criterios de eficiencia institucional. (Alverno College Office, 1998, p. 61)

El siguiente es un esquema simplificado de la nueva estructura organizativa, que es dinámica, y se va configurando y readaptando con el tiempo.

\section{Figura 1}

\section{AIE-UCA. Esquema de la estructura organizativa}

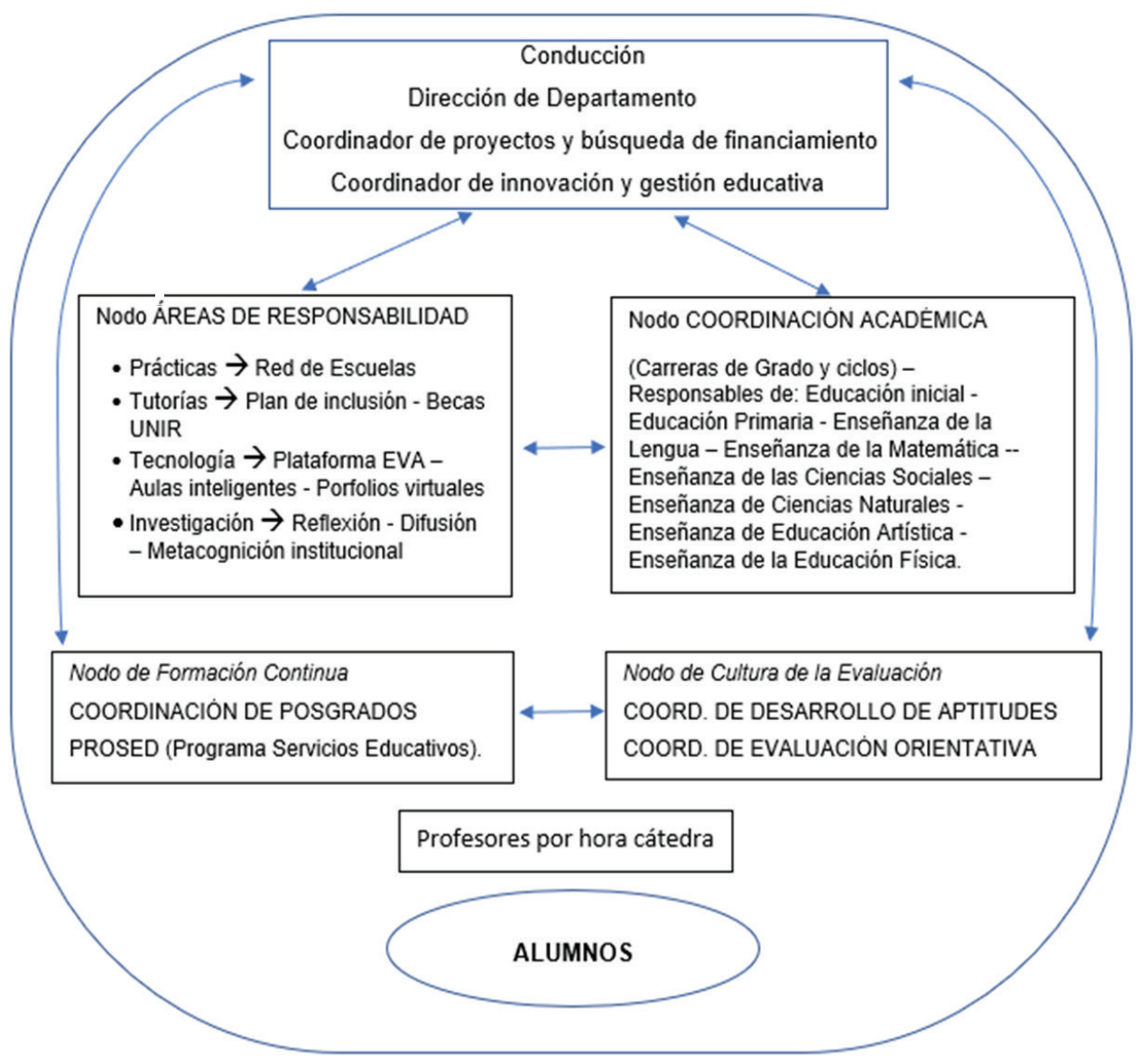

Nota: elaboración propia con base en documentos institucionales UCA-AIE.

12 - Ciencia y Educación 2022; 6(1, enero-abril): 7-26 • Artículos de investigación 
El Departamento de Educación de la UCA, que desarrolla el modelo AIE, se inserta dentro de la Facultad de Ciencias Sociales. Existe una Dirección del Departamento que está acompañada por dos áreas: una de coordinación de proyectos y otra de coordinación y resguardo de la innovación. Ambas tienen funciones de asesoramiento a la Dirección, pero también de gestión de sus áreas específicas; esta impronta multifunción es propia de toda la organización.

Continuando con la descripción, cada uno de los nodos tiene su lugar y su tarea; el más importante es el referido a Cultura de la Evaluación, porque instala una idea fuerza casi contracultural en el mundo de la formación docente, por lo menos en América Latina. Ambas coordinaciones de este nodo (Aptitudes y Evaluación) son la cara y la contracara de la cultura de la evaluación: una fija los estándares (Aptitudes) y otra da los elementos para lograr los objetivos (Evaluación). La Coordinación de Desarrollo de Aptitudes tiene como objetivo acompañar la instalación de una propuesta didáctica centrada en el hacer profesional. Muy apoyada en las premisas de EpC trabaja con la producción de DC a cumplir a lo largo de una serie de estándares escalonados explícitos y acordados. Estos estándares son los que utiliza la Coordinación de Evaluación Orientativa como "vara" para todas las actividades de evaluación (externa, entre pares, autoevaluación) que en el modelo se caracteriza como "evaluación orientativa", porque toma la forma de retroalimentación, necesaria para la competencia de aprender a aprender a lo largo de toda la vida.

El nodo restante, de Formación Continua, se compone de una instancia en desarrollo: los posgrados, y del Programa de Servicios Educativos (PROSED) con larga trayectoria en la Universidad (desde la constitución del modelo es el espacio de actividades de difusión y de formación continua de la docencia interesada en él).

En lo que respecta a la estructura matricial, esta se expresa especialmente en el funcionamiento de los dos nodos restantes; por un lado, el que reúne las Áreas de Responsabilidad y, por el otro, en que se ocupa de las Carreras de Grado (Profesorado de Nivel Inicial y de Nivel Primario y Licenciatura en Educación Inclusiva y Efectiva) y Ciclos (Profesorado Superior y Licenciatura en Dirección y Supervisión Educativa). Sus tareas se entrecruzan y son asistidos por el Coordinador Académico, quien se ocupa de los temas correspondientes a una secretaría académica y además toma como su responsabilidad la asistencia a las Carreras de Grado y Ciclos. En ese entrecruzamiento, una parte de la matriz tiene que ver con los ciclos y niveles en los que se estructura la educación, pero eso se cruza con cuatro temas centrales para el modelo: la práctica profesional, las tutorías, la tecnología y la investigación, que tienen perfil propio dentro del modelo.

- La práctica profesional, que se realiza desde el primer año, tiene un doble perfil: se desarrolla en las escuelas, pero también como parte del aprendizaje correspondiente en cada unidad curricular. Hay especial interés en que sea muy intensiva y diversa, dada la necesidad de hacer experiencia (e instrumentarla) para la inclusión. Como un nodo diferente, pero relacionado, se creó la Red de Escuelas AIE, que empezó a funcionar dos ańos antes del inicio de las carreras, en la etapa de formación del claustro, y funciona como un espacio de Ateneos de Aprendizaje y reflexión de escuelas que se comprometen, por un lado, a innovar en sus propias instituciones y, por el otro, a recibir alumnos practicantes. Este es un grupo de escuelas donde se realiza la práctica profesional, pero se cuenta también con otros centros (más "tradicionales") para ofrecer a los futuros docentes contactos con espacios diversos.

- Las tutorías, cuyo rol es acompañar a los estudiantes a lo largo de su trayecto formativo. Todos los profesores son tutores de 15 alumnos como máximo (de $1^{\circ}$ a $4^{\circ}$ ańo) y los acompañan en su trayectoria académica y personal, individual o grupalmente. Se realiza también tutoraje entre pares de alumnos. El modelo AIE (tutorial) integra en las aulas alumnos de diversa situación socioeconómica con el fin de ofrecer espacios experienciales 
de formación en la diversidad. Se aprovecha para esto el Programa-UNIR Educación que existe en la UCA y que promueve el acceso, la permanencia y el egreso de colectivos vulnerables en la educación superior, desde una cultura del encuentro que valora la diversidad (9).

- La tecnología, que está integrada a la práctica cotidiana. El Departamento cuenta, al igual que la Universidad en su conjunto, con una plataforma online EVA (Entornos Virtuales de Aprendizaje). Cada unidad curricular posee su e-aula, en la cual los futuros docenes interactúan, suben sus desempeños y reciben retroalimentación. Todas las unidades curriculares son híbridas, desde 2017. Hay actividad presencial pero todas poseen aula virtual. Cada alumno configura su portafolio digital (E-portfolio), cuyo contenido debe defender (hacer evidente el aprendizaje) para obtener su grado. Hay especial interés en el uso didáctico de las herramientas digitales. Para esto, el responsable de ese espacio asesora al claustro, organiza capacitaciones y trabaja de manera directa con los alumnos futuros docentes.

- La investigación, que todavía es un trabajo casi individual expresado en las publicaciones de los profesores; cuestión que se asemeja a los desafíos que existen en diversas instituciones de formación docente en la región (Perines, 2021). No obstante, existen criterios comunes para conformar un reservorio de experiencias que evidencien buenas prácticas y sus desafíos. Estas prácticas son objeto de evaluación (retroalimentación) en reuniones del claustro docente.

\section{El claustro de profesores}

El claustro está formado por dos tipos de profesores: los nombrados por cargo, que totalizan 17 , quienes además de dar clase tienen una función institucional asignada; y 34 más contratados por horas cátedra y cuya tarea es dar clase. La carga horaria de los profesores es diferente, oscilando entre 24 y 30 horas semanales. El Departamento está abierto formalmente desde de las 9:00 a. m. hasta las 7:00 p. m. (10). Un $20 \%$ de los profesores tiene grado de doctor y un $40 \%$ de magíster; el resto ha completado especializaciones o cursa maestrías o doctorados.

Los profesores son contratados a través de convocatorias abiertas. Existe un concurso de antecedentes y desempeño (se pide una producción específica relacionada con la temática) que se debe defender ante un tribunal compuesto por profesores de la UCA más un externo calificado.

Una vez por semana (miércoles) los alumnos no concurren a clase. Esto hace posible que los profesores participen del Taller de Desarrollo Profesional (2:00 p. m.-6:00 p. m.) donde se acuerdan prioridades, se discuten temáticas específicas, se analiza la situación de los estudiantes o se invita a un especialista para una presentación calificada.

Otra actividad importante del claustro es la tarea del Equipo Docente de Acompañamiento (EDA), encargado de dar la inducción inicial y acompañar la formación continua de los docentes que ingresan al Departamento de Educación, así como de ofrecer a todo el claustro un plan de formación permanente que afiance la apropiación del modelo AIE y asegure su mejora permanente. A los efectos de contar con un instrumento que ayude a seguir estos lineamientos, se editan el Manual del Alumno AIE y el Manual del Profesor AIE, que se actualizan anualmente para adaptarlos a las mejoras que el modelo va incorporando.

\section{El desarrollo de la profesionalidad}

El modelo AIE-UCA presta mucha atención al análisis de su propio proceso de implementación, gestión y resultados. Una máxima adoptada expresa que gestionar es "crear las condiciones del hacer" para que las cosas sucedan de acuerdo con la visión definida, el diseño institucional y los objetivos planteados (11); esta cuestión genera un saber de experiencia que se torna, a su vez, cultura institucional.

Los postulados innovadores de la propuesta de formación docente AIE-UCA, puestos en práctica 
como respuesta a clásicos desafíos de la formación inicial en diferentes regiones del mundo, son:

1) Aprender a aprender,

2) La reflexión y la autoevaluación conducen a la mejora permanente,

3) El conocimiento es inseparable de su aplicaciónlacción,

4) Saber incluir supone haber pasado por la experiencia de inclusión,

5) Formar ciudadanos del mundo para un mundo global,

6) La tecnología es una competencia transversal,

7) El vinculo formación docente inicial-formación continua retroalimenta el AIE.

Estos postulados-respuestas, que se desarrollan en las siguientes páginas y se sustentan con evidencias extraídas de los E-portfolios, no deben visualizarse como aspectos aislados, sino como hilos de una trama organizacional compleja y estratégica, coordinada e integral, que se evidencia ex post facto. Esto conforma un modelo de formación docente que genera un modo de hacer, un saber de experiencia que se vuelve aprendizaje y cultura institucional, que contribuye (12) a generar resultados específicos en el desempeño organizacional y en las trayectorias académicas de los estudiantes.

\section{Una propuesta de Formación Docente Inicial para aprender-a-aprender}

La sociedad del conocimiento, la información y la complejidad requiere de profesionales capaces de continuar aprendiendo durante toda la vida. Esta cuestión, largamente declamada y menos veces evidenciada, se explicita al expresar que el "fin en mente" es lograr que los estudiantes (futuros docentes) "aprendan a aprender". No se busca que egrese un "profesional experto", sino un "novato" sólidamente formado que "merezca su primer día de clase" y continúe aprendiendo a través de su desempeño profesional (formación docente continua). Se diseñan para tal fin diferentes productos/actividades, y en distintos planos, tales como:

a) Una malla curricular para el desarrollo progresivo de las aptitudes durante toda la carrera que especifica cuáles se enseñan/aprenden en cada unidad curricular (UCA, 2015).

b) Un modelo común de programa de unidad curricular (13) estructurado para contribuir al desarrollo de las aptitudes y acordado en el claustro docente. Cada unidad curricular (recorte de contenidos-despliegue de aptitudes) contiene un corpus teórico que será apropiado por los futuros docentes a lo largo de su formación y "puesto en acción" a través del desarrollo de las cinco aptitudes.

a) Entrevistas individuales a la mitad de la trayectoria formativa y al momento de finalizarla (defensa de E-portfolio), donde los estudiantes identifican por escrito, y a través de los diferentes DC realizados, fortalezas y desafíos en el aprendizaje de las cinco aptitudes según determinados niveles de logro y evidencias de aprendizaje emergentes de la autoevaluación y la retroalimentación recibida.

b) Una dinámica de trabajo con otros (alumnos, profesores, docentes de escuelas), que habitúa a conformar comunidades de aprendizaje.

c) Esto se evidencia en el E-portfolio de una estudiante de cuarto año:

d) Mientras que en mi escolaridad me acostumbré a memorizar y trabajar en solitario, en el profesorado aprendí a aprender de y con otros, no solo con mis compañeros, sino también con cada profesor. Aprendí a retroalimentar y ser retroalimentada, desde el lugar de la escucha, para valorar y sugerir (aptitud de comunicación). Esto garantizó que en conjunto formemos una verdadera comunidad de aprendizaje que logra desarrollar al máximo sus potencialidades y es capaz de realizar la mejor versión de sus desempeños actuando flexiblemente con lo que sabe (Perkins, 1999. Aquí encuentro 
uno de los grandes desafíos de mi práctica profesional, crear comunidades de aprendizaje auténticas. (E-portfolio $\left.N^{\circ} 22,2020\right)$

\section{La reflexión y la autoevaluación conducen a la mejora permanente}

El desarrollo de la habilidad de aprender a aprender requiere de habilidades que se vuelvan parte del habitus profesional: metacognición, autoevaluación, retroalimentación. Estas habilidades, previstas estructuralmente y para cada unidad curricular, se promueven desde diferentes y complementarios espacios, dado que se reflexiona de forma permanente, individual y colectiva, acerca de avances y dificultades en el desarrollo de las aptitudes. La metacognición permite a los estudiantes ser protagonistas en el desarrollo consciente de sus aptitudes. Reflexionando individual y colectivamente sobre las experiencias pueden apropiarse reflexiva y sistemáticamente de ellas incorporando conocimiento científico.

Estos cuatro años de formación me permitieron conocer que mi tarea como docente implica también un trabajo metacognitivo de mis prácticas. De esta manera, comprendo la necesidad de reflexionar y autoevaluar cada una de mis tareas para reconocer lo que logro de forma satisfactoria y detenerme en lo que realmente debo mejorar. En pocas palabras, diría que he aprendido a evaluar mis desempeños y cómo me gustaría enseñarles a mis alumnos en un mańana a evaluar los suyos. (E-portfolio $\left.N^{\circ} 31,2020\right)$

Esto conlleva la intención de hacer responsables a los estudiantes por su proceso de aprendizaje y dar herramientas para tomar conciencia de las dificultades y resolverlas, asumiendo institucionalmente la búsqueda de respuestas a las problemáticas que se "arrastran" a nivel formativo desde experiencias previas.

La reflexión constante sobre la propia práctica es uno de los aprendizajes que más destaco del modelo AIE. Creo que este aspecto contribuye a mi crecimiento docente, potencia la capacidad de autoeva- luarme, de trabajar con mis pares, de intercambiar retroalimentaciones y me invita a no quedarme estática y a desnaturalizar lo naturalizado. Pero por sobre todo, fomenta en mí la acción de mejorar lo realizado con el objetivo de enriquecer el aprendizaje de los estudiantes y el propio. Algunas evidencias que demuestran mi desempeño reflexivo son los diálogos con mis pares y profesoras sobre lo transcurrido en la práctica, la búsqueda de fundamentos sólidos que respalden mis decisiones pedagógicas y las reelaboraciones de los planes de clases a partir de lo reflexionado. (E-portfolio $\left.N^{\circ} 12,2020\right)$

El instrumento principal diseńado para esto es un marco específico y propio de evaluación (Reglamento de Evaluación aprobado por la Universidad y acordado por el claustro docente) que oficia como encuadre común de contenido y forma para todas las instancias de aprendizaje, contribuyendo a crear una cultura evaluativa y de mejora. Esto significa que, si bien existe una calificación numérica final (examen), durante la cursada no se realizan valoraciones cuantitativas sino cualitativas. Todas las unidades curriculares prevén entre dos y tres DC (integrales) que apuntan al desarrollo de dos o tres aptitudes específicas. La autoevaluación de los estudiantes se focaliza en el despliegue profesional del conocimiento integrando teoría, práctica y posicionamiento ético en las aptitudes de cada unidad curricular.

El Desempeño 2 de la Unidad Curricular Evaluación II evidencia (...) la aptitud de Conceptualización (...) fui capaz de realizar sugerencias pertinentes y coherentes con el grupo etario de niños, logrando que reflejen propuestas de mayor autenticidad. Además, pude sugerirle a ambos docentes alternativas creativas respecto de cómo evaluar. Por otro lado, logré realizar una retroalimentación completa, mencionando valoraciones, inquietudes y sugerencias. Fui capaz de respaldar mis sugerencias propuestas a partir de los documentos curriculares y la bibliografía utilizada en la Unidad Curricular, mencionándolos de manera significativa y contribuyendo a la comprensión de las sugerencias realizadas. (E-portfolio $\left.N^{\circ} 5,2020\right)$ 
Todos estos DC cuentan con criterios de evaluación, rúbricas e instrumentos de autoevaluación estipulados y acordados y diferentes tipos de retroalimentación (de docentes a estudiantes, de estudiantes entre sí y de estudiantes hacia docentes). Existen además DC interdisciplinares que cubren más de una unidad curricular.

\section{Figura 2}

Extracto de rúbrica de auto y coevaluación de una unidad curricular

\begin{tabular}{|c|c|c|c|c|c|c|}
\hline \multirow{2}{*}{\multicolumn{2}{|c|}{$\begin{array}{l}\text { Autor: } \\
\text { Mi. } \\
\text { Aptitud/Aspect }\end{array}$}} & \multicolumn{4}{|l|}{ Niveles } & \multirow{2}{*}{$\begin{array}{l}\text { Evidencias y desafíos: Aquí incluir } \\
\text { evidencias de su autoevaluación y } \\
\text { desafíos que se les plantean a futuro } \\
\text { en relación a ella }\end{array}$} \\
\hline & & Nivel 1 & Nivel 2 & Nivel 3 & Nivel 4 & \\
\hline $\begin{array}{l}\text { C } \\
\text { O } \\
\text { N } \\
\text { C } \\
\text { E } \\
\text { P }\end{array}$ & \begin{tabular}{|l|} 
Se \\
conceptualiza \\
correctamente \\
el proyecto y su \\
fundamentación
\end{tabular} & $\begin{array}{l}\text { El proyecto no está } \\
\text { fundamentado } \\
\text { según los criterios } \\
\text { especificados en la } \\
\text { consigna. }\end{array}$ & $\begin{array}{l}\text { La fundamentación del proyecto no } \\
\text { considera las características específicas } \\
\text { del grupo de niños, o no considera el } \\
\text { desarrollo cognitivo teórico de niños } \\
\text { de esa edad, o no toma en cuenta la } \\
\text { propuesta curricular, o no fundamenta } \\
\text { las capacidades a trabajar, o no } \\
\text { presenta un abordaje interdisciplinar. }\end{array}$ & $\begin{array}{l}\text { La fundamentación del proyecto considera: } \\
\text { 1. Lo adecuado y relevante del recorte para las } \\
\text { características específicas de los niños y su } \\
\text { desarrollo cognitivo teórico. } \\
\text { 2. La pertinencia curricular e interdisciplinaria del } \\
\text { recorte. } \\
\text { 3. La viabilidad institucional. } \\
\text { 4. Las capacidades a trabajar y su justificación. } \\
\text { 5. El abordaje didáctico de las áreas involucradas. }\end{array}$ & $\begin{array}{l}\text { Además de lo previsto para } \\
\text { el nivel III se presenta en la } \\
\text { fundamentación una } \\
\text { articulación de las didácticas } \\
\text { areales (por ejemplo el uso } \\
\text { de los conceptos areales de } \\
\text { Cs.Ss.) }\end{array}$ & $\begin{array}{l}\text { Logramos desarrollar una } \\
\text { fundamentación que integra los } \\
\text { distintos aspectos del proyecto, } \\
\text { utilizando flexiblemente varios de los } \\
\text { marcos conceptuales aprendidos } \\
\text { durante estos años de formación: } \\
\text { tanto la enseñanza basada en } \\
\text { capacidades, como los } \\
\text { conocimientos de cada área, las } \\
\text { didácticas areales y la psicología } \\
\text { evolutiva. } \\
\text { A su vez, la conceptualización fue } \\
\text { abordada desde distintos autores y } \\
\text { material bibliográfico. }\end{array}$ \\
\hline $\begin{array}{l}\text { T } \\
\text { U } \\
\text { A } \\
\text { L } \\
\text { I }\end{array}$ & \begin{tabular}{|l|} 
Se \\
conceptualiza \\
bien el trabajo \\
con capacidades \\
/aptitudes \\
\end{tabular} & $\begin{array}{l}\text { No se toman en } \\
\text { cuenta las } \\
\text { aptitudes/ } \\
\text { capacidades a } \\
\text { trabajar con los } \\
\text { niños o se las }\end{array}$ & $\begin{array}{l}\text { El proyecto incorpora capacidades pero } \\
\text { no se incorporan en la fundamentación, } \\
\text { o no se traslucen en los objetivos. }\end{array}$ & $\begin{array}{l}\text { El Proyecto incorpora las capacidades siguiendo los } \\
\text { siguientes criterios: } \\
\text { 1. Se mencionan y definen incluyendo su } \\
\text { 2. Se justifíca su elección en la fundamentación } \\
\text { 3. Los obietivos se redactan en función de ellas }\end{array}$ & $\begin{array}{l}\text { Además de lo establecido en } \\
\text { el nivel III, las definiciones } \\
\text { de las capacidades parten de } \\
\text { lo propuesto por IPA o el } \\
\text { curriculum y son } \\
\text { enriouecidas en función del }\end{array}$ & $\begin{array}{l}\text { Siguiendo las definiciones brindadas } \\
\text { en el documento de los IPA } \\
\text { definimos desde un principio las } \\
\text { capacidades que queriamos que los } \\
\text { alumnos desarrollen a lo largo del } \\
\text { a }\end{array}$ \\
\hline
\end{tabular}

Nota: Fragmento de rúbrica de autoevaluación recuperada de la plataforma de aprendizaje virtual EVA UCA, 2020.

\section{El conocimiento es inseparable de su aplicación/ acción}

Las aptitudes son combinaciones complejas de conocimientos, actitudes y procedimientos que tienden a lograr una formación integral que una "manos, cabeza y corazón” (Papa Francisco, 2019): saber - saber hacer - saber ser. Contrariamente a la formación enciclopedista que valora únicamente la razón (o la memoria), se promueve el desarrollo de una experiencia formativa que sea praxis e involucre la totalidad de la persona (acción reflexionada y saber/conocimiento en acción). Es decir, una didáctica disruptiva vivida en la formación docente inicial permite a los estudiantes apropiarse del saber internalizando sus experiencias formativas conscientemente, cuestión que facilita su transferencia.

Durante mis años de formación en el modelo AIE, aprendí que el docente no debe ser transmisor de conocimientos, sino más bien un facilitador, acompañante y guía (...) realiza lo necesario para diseñar propuestas de enseñanza contextualizadas que les permitan a los estudiantes situarse en un rol determinado, emprenderse en un desafío, desarrollar capacidades y valores, y trabajar en equipo para construir sus propios aprendizajes. (...) un buen docente debe concebir a los estudiantes como protagonistas del proceso de enseñanza y concuerdo con Davini (2015) cuando afirma que estos deben comprender que el educador no es el centro de dicho proceso. Por este motivo, considero que al planificar siempre tengo en cuenta las características de los estudiantes, sus intereses y su contexto. Además, trabajo para brindarles un rol activo que les permita implicarse en la situación didáctica. (E-portfolio $\left.N^{\circ} 17,2020\right)$

Estas premisas orientan el diseño de DC que permiten evidenciar el nivel de logro en el aprendizaje de las aptitudes. Los DC son actividades complejas 
que invitan a poner en acción el saber, el hacer y el ser; suponen diferentes "desafíos de las inteligencias" bajo la consideración de que (todos) los seres humanos estamos "programados para aprehender" (Freire, 1993) y que esos procesos suceden a nivel individual y en la interacción con otros.

Durante la segunda parte de las residencias logré desarrollar la aptitud de diagnóstico, ya que al planificar pude tener en cuenta los siguientes elementos: las características de los estudiantes, los recursos que estos utilizan para respaldar su aprendizaje, las estrategias didácticas y/o dinámicas efectivas que desarrollan junto a la docente titular y las modalidades de trabajo propuestas por la institución educativa. Es decir que pude "diagnosticar las necesidades de los alumnos sobre la base del conocimiento y de la comprensión de sus realidades" (UCA, 2020, p. 13). Pude lograr todo esto, a partir de la relectura del perfil teórico de los niños (realizado en las Prácticas Educativas III), de las observaciones de las clases virtuales, de las consultas que le realicé a la docente titular del grupo y de los intercambios con mi profesora de prácticas. De esta forma, observé para luego planificar decisiones pedagógicas y seleccionar recursos efectivos que me permitieron adaptarme a ciertos elementos del contexto escolar que potencian el aprendizaje de los niños, por ejemplo: mantener las actividades de trabajo en grupo, diseñar una hoja de encuentro tal como la institución lo solicita, utilizar una pizarra analógica, proporcionar diversos recursos para resolver las situaciones problemáticas, etc. (E-portfolio $\left.N^{\circ} 6,2020\right)$

\section{Saber incluir supone haber pasado por la expe- riencia de inclusión}

El derecho a la educación, entendido como inclusión, no es dar a todos lo mismo, sino a cada uno lo que necesita en el marco de procesos individuales y grupales de aprendizaje que nos constituyen parte de una aldea global (Peregalli, 2020). Este es un desafío local e internacional para el desempeño docente (Hernández Izquierdo \& Marchesi, 2021). El modelo AIE-UCA incluye estar en grupos-clase socialmente heterogé- neos, integrados por estudiantes que provienen de diferentes sectores socioculturales, haciendo posible una experiencia de inclusión con todos los desafíos que esto implica y realizando prácticas en instituciones formales y no formales, de gestión estatal, privada y social, confesional y no confesional.

Soy de la Villa 21-24 (...) Dejé la carrera anterior porque no me gustaba y me sentí muy discriminada (...) cuando se me presentó otra oportunidad elegí la UCA, tenía miedo de que la experiencia fuera la misma y que volviera a dejar pero dije 'con probar no pierdo nada'. Ingresé en la institución y me sentí muy acompañada acá, porque al ser de un barrio bajo no me discriminaban sino que valorizaban la experiencia que yo tenía; a medida que yo iba cursando me sentí muy cómoda y además tenemos un programa de tutorías donde siempre remarcaban esto, que ser de un barrio vulnerable no es malo sino que al contrario tenemos muchas experiencias que enriquecen a todos mientras se van contando. (E-portfolio $\left.N^{\circ} 15,2020\right)$

(...) la posibilidad de realizar prácticas en contextos totalmente opuestos, desde colegios de clase alta en el centro de la Ciudad Autónoma de Buenos Aires hasta espacios no formales en los sectores más desfavorables. Ante esto aprendí a ponerme los 'lentes' necesarios para mirar con detenimiento a cada nińo en su contexto, detectando sus características, sus necesidades y sus potencialidades. Cabe mencionar también que aprendí que la inclusión no sólo se refiere a incluir a niños con discapacidad, sino lograr incluir a cada uno para que encuentren su lugar y puedan desempenarse integralmente. (...) aprendí que un docente inclusivo y efectivo atiende a las necesidades de cada uno de los estudiantes y elimina las barreras sociales para incluir a todos. Por lo que comencé a actuar en base al concepto de equidad, a partir del cual le doy a cada estudiante lo que necesita y no a todos lo mismo (interacción inclusiva). (E-portfolio $\left.N^{\circ} 28,2020\right)$ 
Se promueve la valoración del otro y lo otro como enriquecedor de la vida humana y como experiencia clave para el desarrollo de la profesión. A efectos de contribuir a que eso suceda se cuenta con: espacios específicos de acompañamiento de las trayectorias (tutorías); estrategias para favorecer la inclusión de todos los estudiantes en el grupo clase y en el proceso de aprendizaje (Programa de Inclusión Educativa UNIR-Educación); abordaje de situaciones específicas de estudiantes en las reuniones semanales del claustro docente, jerarquizando lo pedagógico como cuestión central y el protagonismo y la autonomía de los estudiantes (Peregalli \& Gómez Caride, 2020). Esto se evidencia en las siguientes expresiones:

Considero que el AIE es una experiencia inclusiva y efectiva porque: incluye a estudiantes de diferentes contextos sociales, culturales y económicos, brindando oportunidades para que cada uno se sienta incluido y aprenda óptimamente; brinda oportunidades de crecimiento, tanto personal como profesional; promueve el trabajo en equipo y el desarrollo de capacidades en cada estudiante. (E-portfolio $\left.N^{\circ} 31,2020\right)$

\section{Formar ciudadanos del mundo para la aldea global}

La aldea global requiere docentes globales que eduquen para un mundo poliédrico y multicultural (Papa Francisco, 2019). El modelo AIE-UCA enfatiza la formación de ciudadanos globales que se abren al campo cultural y a la globalización, con una ética solidaria (dimensión política) que se responsabiliza por la construcción de la polis y el orbe desde humanismo solidario. Para eso se diseñan espacios curriculares y experiencias formativas inclusivas (de compromiso social, aprendizaje-servicio solidario) en instituciones educativas de diferentes tipos de gestión, en diferentes ámbitos y modalidades que contribuyen a formar un docente que enseñe "todo a todos".

Evidencias relativas al desarrollo de una perspectiva global surgen del análisis de experiencias desarrolladas en el espacio curricular denominado Trayecto
Formativo Personalizado. Este ámbito, que oficia como ventana al mundo del presente y el futuro, incluye conversatorios con científicos, con emprendedores en campos diversos, promueve las visitas a museos, muestras de arte, y la participación en expresiones artísticas y culturales (14), junto a la reflexión al respecto.

Hace un mes terminé de leer Yo soy Malala, la protagonista y autora del libro cuenta su historia en Pakistán, país donde nació. Con tan solo doce años de edad, Malala luchó por su derecho y el de todas las mujeres, el derecho a la educación. No pretendo contarles la historia, mejor prefiero recomendarles que la lean. Mujer empoderada si las hay, fuerte y valiente. Luchó y hasta casi dio su vida por su país, por las mujeres y el futuro (...) Este libro me hizo desarrollar una perspectiva global (...) poder apreciar las conexiones económicas, sociales y ecológicas que vinculan a las naciones y las personas, me quedé pensando en la cantidad de conexiones entre los distintos poderes de los países que se ponen en juego a la hora de hablar de educación. (DC, estudiante de tercer año, 2019)

Otras evidencias con relación a este postulado son las expresiones de estudiantes de segundo año del Profesorado de Nivel Primario que, en el segundo cuatrimestre de 2020, y en el marco de la Práctica Educativa, llevaron adelante un proyecto de Compromiso Social (aprendizaje y servicio solidario) en un Colegio que trabaja con población vulnerabilizada:

Aprendí más de lo que me imaginaba. No me di cuenta de que en realidad estas eran mis prácticas, realmente las disfruté muchísimo. Aprendí a planificar, basándome en las necesidades sociales, educativas y económicas de las familias. (DC, estudiante de segundo año, 2020)

(...) esta experiencia profesional tuvo cómo eje central la reflexión sobre la diversidad de las aulas, la heterogeneidad de los contextos, la especificidad de los alumnos y sus perfiles de aprendizaje. Las dificultades presentadas fueron una oportunidad para aprender y valorar la riqueza de la diferencia, encontrándonos nosotros en ella (...). (DC, estudiante de segundo año, 2020) 


\section{La tecnología es una competencia transversal}

El mundo contemporáneo requiere profesionales de la docencia que integren las tecnologías de la información y la comunicación como parte de su desempeño (de cómo pensar el aprendizaje) y no como un "agregado esporádico o marginal". En este sentido, las tecnologías se insertan en el Triángulo Didáctico conforme al modelo ICT-TCPK (Valverde et al., 2010) integrando el conocimiento tecnológico al pedagógico, como herramienta de interacción al servicio de un conocimiento, un contexto, un sujeto y una finalidad específica. De este modo, los docentes habrán configurado su identidad con este aspecto como característica distintiva de su desempeño.

(...) la primera parte de la Residencia Pedagógica consistió en planificar una secuencia didáctica sobre las olas inmigratorias del Siglo XIX y la vida de los inmigrantes al llegar a Argentina para alumnos de sexto grado, realizada virtualmente en la plataforma SM-Conecta. Para conceptualizar este tema me remití a mi historia familiar (...) tomé como uno de los recursos para motivar a los estudiantes un video testimonial realizado por mi tía (Enlace al recurso), quien vive desde que nació en mi casa, que es un ex conventillo, y convivió con muchos inmigrantes cuando era niña. (E-portfolio $\left.N^{\circ} 35,2020\right)(15)$

El trayecto académico en el modelo AIE-UCA combina, desde el momento de su creación (2017), presencialidad y virtualidad en cada uno de los espacios curriculares e instancias específicas de formación. En tal sentido, el E-portfolio digital, que estructura la entrevista de portfolio para los estudiantes del último año de la carrera, oficia como cierre de su trayecto formativo y "carta de presentación profesional" para el estudiante próximo a egresar.

\section{Figura 3}

Fragmento de E-portfolio (N4, 2020)

\section{cCOMO D \\ ¿CÓMO DESARROLLÉ ESTA APTITUD?}

El mapa conceptual presentado corresponde a una parte del Desempeño Final de la Unidad Curricular Ciencias Naturales y su Enseñanza.

Es evidencia de la aptitud de conceptualización en los ejes 1 (autorreferencial) y 3 (en interacción con la disciplina y el campo disciplinar). Algunos de los descriptores de estos ejes tienen como foco la habilidad de dominar el contenido disciplinar, identificar las ideas centrales, plantearse preguntas y responsabilizarse por conocer el área que le toca enseñar (UCA-AIE, 2020).

La red diseñada establece conexiones entre los diferentes conceptos involucrados en un tema puntual del área de las Ciencias Naturales (el elegido para aquella planificación): "la corriente eléctrica" y además incluye conceptos de unidades didácticas previas, como "los seres vivos".

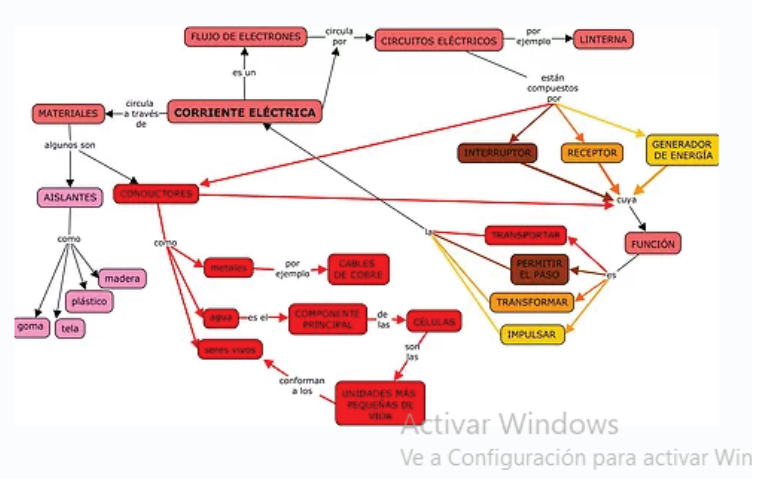


La formación docente inicial y la formación docente continua se retroalimentan

Existen en el mundo experiencias de instituciones formadoras de docentes que se asocian con escuelas inclusivas y efectivas, que incluyen y enseñan a todos los alumnos respetando sus diversas necesidades. Los resultados muestran que esas prácticas, y el trabajo en red, promueven mejoras en tres aspectos: en los saberes y desempeños de los docentes; en las actitudes y disposiciones de los estudiantes de formación docente; y en los logros educativos de los estudiantes de las escuelas (Guevara \& Zacarías, 2016). El vínculo y el trabajo en red constituyen una vía de mejora de la formación docente inicial y continua y, en consecuencia, de la equidad y calidad de la educación que brindan las escuelas. El modelo AIE-UCA lidera el desarrollo de una Red de Escuelas que asocia un centenar de heterogéneas instituciones. Se trata de una comunidad de práctica que conecta la Formación Docente Inicial (FDI), es decir, los estudiantes y docentes de los Profesorados de Nivel Inicial y Nivel Primario de la UCA, con la Formación Docente Continua (FDC), que son los directivos y docentes pertenecientes a las escuelas asociadas. La red se sustenta en las buenas y exitosas experiencias internacionales que aluden a la potencia y el enriquecimiento mutuo entre la FDI y la FDC, cuando no solo se coordinan "acciones en vistas de la práctica” sino, y sobre todo, misiones, visiones, objetivos; marcos epistémicos, pedagógicos y didácticos acerca de lo educativo y sus desafíos en el siglo XXI (Peregalli, 2021; Azar et al., 2020). La red propone un ciclo bianual de trabajo que focaliza, por un lado, en la gestión de la innovación institucional (año 1) y, por otro lado, en el diseño, la implementación y la evaluación de experiencias de aprendizaje inclusivas y efectivas (año 2). La siguiente cita evidencia el vínculo FDI-FDC que sustenta la Red y sus resultados:

Hace tres años nos unimos a la Red de Aprendizaje Inclusivo y Efectivo de la UCA. Pertenecer a la Red nos permitió, por un lado conocer nuevas formas de enseñar y aprender, desde el enfoque de la enseñanza para la comprensión. Pero también nos permitió acceder a experiencias de otros colegas y otras instituciones y fundamentalmente nos alentó a iniciar un camino hacia la transformación institucional desde la innovación, la práctica reflexiva y la búsqueda constante de la mejora que acerque a cada uno de nuestros alumnos el desarrollo de las capacidades necesarias para desarrollar su propio proyecto de vida. Somos conscientes de que esto no es sencillo, que implica desafiar nuestras prácticas y nuestro saber, incomodarnos y sobre todo seguir aprendiendo. Pero esto es posible en el marco del trabajo de un equipo comprometido y sumamente profesional, junto a una red que contiene, ofrece oportunidades y despierta inquietudes para seguir avanzando. (Vicedirectora de Nivel Inicial y Nivel Primario de Escuela Asociada a la Red AIE, 2020)

\section{Conclusiones y discusiones}

El análisis de esta experiencia, desde la teoría de innovación que lo sustenta, evidencia la importancia de implementar reformas en la formación docente inicial que superen la mera mejora de aspectos marginales de las propuestas tradicionales. En este sentido, la innovación que aquí se presenta (AIE-UCA) denota resultados y plantea desafíos. Esto se amplía en este punto del artículo con la intención de mostrar relevantes aspectos de esta innovadora experiencia de formación docente y consignarlos a modo de discusión:

- Resultado 1. Mejora fuertemente la eficiencia interna de la formación docente inicial.

Desafío: ¿Los datos exitosos en esta incipiente experiencia son predictores de un modelo eficiente de formación docente? El acceso a la educación superior en el mundo pasó de un 19\% a un 38\% en las últimas dos décadas (UNESCO-IESALC, 2020). Argentina ha seguido este proceso, pero en los Institutos de Formación Docente las trayectorias estudiantiles presentan resultados preocupantes, particularmente en los primeros años, ya que más del $50 \%$ de los estudiantes interrumpe la cursada durante el primer año (INFoD, 2019, p. 2) (15). En el caso del modelo AIE-UCA, por el contrario, 
de los 200 estudiantes que en 2020 cursaron el AIE en el total de la carrera, el abandono llega solo al 10\%, ya que el $90 \%$ de estudiantes de las respectivas cohortes cumplimenta su trayectoria académica en tiempo y forma (16).

- Resultado 2. Se reduce la desigualdad entre los estudiantes.

Desafío: ¿Es posible sostener estos resultados a lo largo del tiempo? Es de notar que, de los 20 estudiantes del Programa UNIR-Educación (17) que ingresaron entre 2017 y 2020, actualmente 17 continúan con la cursada. El desempeño de este grupo de estudiantes es similar al de la media de estudiantes del Profesorado. Los estudiantes del Programa UNIR-Educación que culminaron su formación en 2020 tienen un promedio de calificación de 8,5 puntos en una escala que va de 1 a 10. Frente a estos datos emerge como desafío el análisis de esta tendencia a lo largo de los años, con estudios de cohortes que, sobre esta línea de base, confirmen o refuten estos alentadores pero todavía incipientes resultados. A su vez, y más interesante aún, que siga arrojando evidencias acerca de los factores que contribuyen a que eso suceda.

- Resultado 3: Se implementa una nueva (y mejor) manera de aprender, un nuevo modelo epistémico, pedagógico y didáctico.

Desafío: ¿La innovación llegará a institucionalizarse, hacerse sostenible en el tiempo y construir conocimiento epistémico, pedagógico y didáctico? La innovación propuesta es una disrupción profunda que transforma las estructuras (organización) y sus contenidos (TD). Un estudio exploratorio realizado en 2017, cuyo objetivo fue describir la experiencia académica de los becarios del modelo AIE-UCA (50\% del total del grupo clase), destacó que "este modelo es diferente y mejor que el modelo tradicional". Los estudiantes afirmaron que el AIE es "una forma de enseñar y de aprender diferente y mejor a lo tradicional” (Gómez Caride, Peregalli, Dellavedova, 2017). El transcurso de los años parece confirmarlo desde las eviden- cias que esos mismos estudiantes expresan en 2020 (año en que egresaron), algunos de cuyos ejemplos se transcribieron en páginas precedentes. Emerge como desafío continuar sosteniendo la experiencia, sistematizarla y adaptarla para crear conocimiento acerca de la epistemología, la pedagogía y la didáctica que la sustenta. Este aporte contribuiría a un área de vacancia en la investigación referida a la formación docente local e internacional (18).

- Resultado 4. Se genera un nuevo modelo organizacional y una reconfiguración del TD.

Desafío: ¿El aprendizaje organizacional está institucionalizado? El modelo AIE-UCA sustenta un diseño político-institucional y organizacional que busca generar las condiciones para hacer posible una nueva identidad docente. Conlleva una disrupción profunda, compleja, estratégica y situada, que da como resultado una institucionalidad innovadora que modifica las estructuras y las formas de hacer - saber - ser, y se retroalimenta a lo largo del tiempo, generando aprendizaje organizacional. Emerge como desafío capitalizar la experiencia para poder escalarla, replicarla y transferirla a otros lugares, otras regiones y otros espacios, identificando puntos críticos y desafíos estratégicos; diseminando la experiencia hacia el sistema formador nacional e internacional.

Este artículo describió el caso AIE-UCA de formación por aptitudes como modelo de innovación disruptiva que contribuye a forjar una nueva identidad docente. El salto cualitativo en la creación de este modelo refiere a la integralidad e interrelación de tres aspectos clave de las instituciones/organizaciones: diseño político-institucionallorganizacional, modos de gestión, resultados (Peregalli, 2017), teniendo como foco en las trayectorias académicas y el logro de aprendizajes inclusivos y efectivos. Esto evidencia un nuevo modo de ser-hacer-saber, una nueva cultura institucional en la formación docente inicial que se compone de hábitos, rutinas, símbolos, acuerdos, espacios, tiempos y una jerga conceptual específica acordada y experimentada (vivida). Capitalizar 
la experiencia AIE-UCA en aprendizajes organizacionales que la nutran y retroalimenten, y que se consoliden e informen al sistema formador en su conjunto y a procesos regionales e internacionales, será un desafío de los próximos años. Analizar cómo se desempeñan en el sistema educativo los nóveles docentes AIE y cuánto contribuyen a su innovación, también lo será. El desafío es profundo y complejo, habrá que seguir soñando y haciendo posible lo que parecía imposible.

\section{Referencias}

Aguerrondo, I. (1993). La calidad de la educación: ejes para su definición y evaluación. Revista Interamericana de Desarrollo Educativo. La Educación, 37(116).

Aguerrondo, I. (2009). Conocimiento complejo y competencias educativas. Unesco-Ibe, 8, 13. http://www.ibe.unesco.org/

Aguerrondo, I. \& Gómez Caride, E. (2019). La formación docente por aptitudes. El caso del Alverno College. Kapelusz.

Aguerrondo, I., Lugo, M. T. \& Rossi, M. (2001). La gestión de la escuela y el diseño de proyectos institucionales. Universidad Nacional de Quilmes.

Aguerrondo, I. \& Sampedro, R. (2020). La Supervisión educativa en un mundo cambiante. Kapelusz.

Alverno College-Office of Academic Affairs. (1998). ¿Cómo funciona y se manifiesta la transformación institucional? En Aguerrondo I. \& Gomez Caride, E. (Coord). La Formación Docente basada en Aptitudes: el caso de Alverno College (65-83). Kapelusz.

Armengol-Asparó, C., Mercader, C. \& Ion, G. (2020). Making peer-feedback more efficient: what conditions of its delivery make the difference? Higher Education Research \& Development. https:// doi.org/10.1080/07294360.2020.1840527

Azar, G. (2020). La gestión efectiva de la enseñanza inclusiva. Kapelusz.

Azar, G., Peregalli, A., Dellavedova, V. \& Gómez, M. (2020). Red de escuelas de innovación AIE-Situación y proyección [Manuscrito no publicado].
Baquero, R. (2002). Vygotski y el aprendizaje escolar. Aique.

Barber, M. \& Mona, M. (2007). How the world's best-performing school systems come out on top. McKinsey \& Company.

Bruer, J. T. (1995). Escuelas para pensar: una ciencia del aprendizaje en el aula. Paidós.

Cardoner, M. \& Ravela, P. (2020). Transformando las prácticas de evaluación a través del trabajo colaborativo. Grupo Magro.

Castells, M. (ed.) (2006). La sociedad red: una visión global. Alianza.

Charmaz, K. (2013). La Teoría Fundamentada en el siglo XXI. Aplicaciones para promover estudios sobre la Justicia Social. En Denzin, N. \& Lincoln, Y. (comps.). Estrategias de Investigación Cualitativa (Vol. III). Gedisa.

Díaz Barriga, F. (2003). Cognición situada y estrategias para el aprendizaje significativo. Revista Electrónica de Investigación Educativa, 5(2).

Diez, M., Athanasiou, N. \& Pointer Mace, D. (2010). Expeditionary Learning: The Alverno College Teacher Education Model, Change, 18-24.

Escrich Gallardo, T., Lozano Aguilar, J. F. \& García Aracil, A. (2015). Competencias Vs. Capacidades: ¿Enfoques complementarios o excluyentes? REFLEX. Cheers.

Freire, P. (1993). Educación y Participación Comunitaria. En Freire, P. Politica y Educación (73-87). Siglo XXI.

Gómez Caride, E., Peregalli, A. \& Dellavedova, V. La inserción universitaria en estudiantes becadas durante en el inicio del modelo AIE-UCA. En UCA, Facultad de Ciencias Sociales, Tercera Reunión sobre Barrios Precarios en las Metrópolis Argentinas. Aportes para intervenciones inclusivas, Buenos Aires, 25 y 26 de septiembre de 2017.

Guevara, J. \& Zacarías, I. (2016). Empezar la docencia en escuelas inclusivas. Documento de Trabajo $\mathrm{N}^{\circ}$ 154. CIPPEC. https://www.cippec.org/ wp-content/uploads/2017/03/1042.pdf 
Hopkins, D. (1996). 'New rules' for the radical reform of teacher education. En Hudson, A. \& Lambert D. (Eds.). Exploring Futures in Initial Teacher Education. Changing Keys for Changing Times. Institute of Education, University of London, Bedford Way Papers.

INFoD. (2019). Politicas para mejorar las trayectorias estudiantiles en la formación docente inicial. Plan de trabajo 2019. Ministerio de Educación, Cultura, Ciencia y Tecnología, Secretaría de Innovación y Calidad Educativa. https://cedoc. infd.edu.ar/wp-content/uploads/2019/12/Politicas-para-mejorar-las-trayectorias-estudiantiles-en-la-formacion-docente.pdf

Hernández Izquierdo, L. \& Marchesi, Á. (2021). Actitudes de los maestros ante la inclusión educativa en Colombia, Guatemala y España. Ciencia y Educación, 5(1), 7-24. https://doi. org/10.22206/cyed.2021.v5i1.pp7-24

McKinsey. (2007). Cómo hicieron los sistemas educativos con mejor desempeño del mundo para alcanzar sus objetivos. McKInsey \& Company.

Muñoz, J. M. E., López, M. T. C. \& Alonso, J. F. T. (2017). Aprendizaje docente y desarrollo profesional del profesorado. Profesorado, 21(3), 83-102. https://doi.org/10.30827/profesorado. v21i3.9970

Nirenberg, O. (2012). Un método para la autoevaluación y la mejora de la calidad educativa. Sistematización de experiencias en escuelas primarias argentinas 2006-2012. UNICEF.

Papa Francisco. (04 de abril de 2019). Audience with participants in the Conference of the International Federation of Catholic Universities (FIUC). Audiencia a los participantes en la Conferencia de la Federación Internacional de Universidades Católicas, Roma, Italia.

Pavié, A. (2011). Formación docente: hacia una definición del concepto de competencia profesional docente. Revista Electrónica Interuniversitaria de Formación Del Profesorado, 14(1), 67-80. https://doi.org/1575-0965
Peregalli, A. (04 de junio de 2021). Aprendizaje inclusivo y efectivo: Red de innovación para la formación docente inicial y continúa. Seminario Internacional "Innovación y mejoras de la formación práctica en la Formación Inicial Docente: Desafíos, tensiones y proyecciones", Universidad Católica del Maule, Chile: https://youtu.be/ CBvoutnYeas

Peregalli, A. (2020). Alianza Estado-Sociedad Civil: Debates y Desafíos en la Co-Gestión de Políticas de Inclusión Educativa en Uruguay y Argentina. Education Policy Analysis Archives. Arizona State University, 28(43), 1-44. https:// doi.org/10.14507/epaa.28.4162

Peregalli, A. \& Gómez Caride, E. (2020). Aprendizaje inclusivo y efectivo. Derecho a la educación superior: transitar del dicho al hecho en una experiencia de formación docente universitaria por aptitudes. En Tuñon, I. \& Poy, S. La educación de los argentinos en clave de recursos y estructuras de oportunidades (pp. 42-47). EDUCA.

Peregalli, A. (23 y 24 de agosto de 2018). Aprendizaje Inclusivo y Efectivo: la tutoría y su rol clave en la construcción de un nuevo modelo de formación docente. I Seminario Latinoamericano de Políticas de Inclusión y Tutoría: una mirada regional sobre las políticas de inclusión en la educación superior, UTN- Facultad Regional Buenos Aires, Argentina.

Peregalli, A. (2017). Alianza Estado-Sociedad Civil: Co-gestión de politicas de inclusión educativa orientadas a adolescentes, jóvenes y adultos en Uruguay y Argentina [Tesis Doctoral, Universidad de San Andrés].

Perines, H. (2021). Investigación educativa en la formación del profesorado: el caso de la Universidad de La Serena. Ciencia y Educación, 5(1), 25-40. https://doi.org/10.22206/cyed.2021. v5i1.pp25-40

Perrenoud, P. (2007). Desarrollar la Práctica Reflexiva en el oficio de enseñar. Graó/Colofón.

Perkins, D. (1999). ¿Qué es la comprensión? En M. C. Pogré, P. \& Stone W. (Ed.), La Enseñanza para la Comprensión (pp. 69-93). Paidós. 
Piovani, J. I. (2018). Reflexividad en el proceso de investigación social: entre el diseño y la práctica. En Piovani, J. I. \& Muñiz Terra, L (Coord.). ¿Condenados a la reflexividad? Apuntes para repensar el proceso de investigación social. CLACSO/ BIBLOS.

Reimers, F.M. (2020). Empowering Teachers to Build a Better World. How Six Nations Support Teachers for 21st Century Education. Springer Briefs in Education.

Rodríguez, H. (2014). La Educación precisa de un Nuevo Paradigma. Revista de Educación Virtual. https://revistaeducacionvirtual.com/ archives/871

Rodriguez, H. (2016). El desafío de una Educación Media inclusiva y de calidad. En Noveduc (Ed.), El desafio de la inclusión en el nivel medio y superior. Noveduc.

Rodriguez, H. (2021). El desarrollo de capacidades profesionales durante la formación inicial de nivel primario en el $A M B A$ [Tesis de doctorado inédita]. Programa Interuniversitario de Doctorado en Educación (UNTreF, UNLa, UNSaM).

Terigi, F. (2012). Los saberes docentes. Formación, elaboración en la experiencia e investigación. Santillana.

Tyack, D. \& Cuban, L. (2001). En busca de la utopía. Un siglo de reformas de las escuelas públicas. Fondo de Cultura Económica.

UCA. (s.f.). Facultad de Ciencias Sociales-Departamento de Educación. Programa UNIR-Educación. Reglamento [Manuscrito no publicado]. http://uca.edu.ar/es/institucional/alumnos/ becas-y-prestamos/programa-de-inclusion-educativa-unir-educacion

UCA. (s.f.). Facultad de Ciencias Sociales-Departamento de Educación. Red de escuelas de innovación AIE. https://www.youtube.com/ watch?v=vuHbj1bknuM

UCA. (2015). Diseño Curricular Profesorado de Educación Primaria [Manuscrito no publicado].

UCA. (2018). Convocatoria de propuestas sobre intervenciones innovadoras. Programa regional para el desarrollo de la profesión docente en América Latina y el Caribe. Banco Mundial [Manuscrito no publicado]. https://desarrollodocente. org/documents/experiences/documents/31/ Postulaci\%C3\%B3n_Banco_Mundial_Documentos.pdf?1529963729

UCA. (2019). Facultad de Ciencias Sociales-Departamento de Educación-AIE. Testimonios de estudiantes de Profesorado de Nivel Inicial y Nivel Primario. https://www.youtube.com/watch?v= GolUIvfyL0s\&feature=youtu.be

UCA. (2020). Manual del futuro docente [Manuscrito no publicado].

UNESCO-IESALC. (2020). Hacia el acceso universal a la educación superior: tendencias internacionales. https://www.iesalc.unesco.org/wp-content/ uploads/2020/11/acceso-universal-a-la-ES-ESPANOL.pdf

Valverde-Berrocoso, J., Garrido Arroyo, M. \& Fernández Sánchez, M. (2010). Enseñar y aprender con tecnologías: Un modelo teórico para las buenas prácticas con TIC (ejemplar dedicado a: Buenas prácticas de enseñanza con TIC), Teoría de la Educación: Educación y Cultura en la Sociedad de la Información, 11(1), 203-229.

Verd, J. M. \& Lozares, C. (2016). Introducción a la investigación cualitativa. Fases, métodos y técnicas. Síntesis.

Vezub, L. (Coord), Borioli, A., Serrudo, A., Serra, J.C., Sartirana, L. \& Galarza, D. (2019). El campo de las prácticas en la formación docente inicial. Organización, funcionamiento y tensiones. Estudio Nacional 2017-2018. INFoD.

\section{Notas}

1) Alverno College: www.alverno.edu

2) Harvard. Graduate School of Education: Project Zero: www.pz.harvard.edu

3) Más fundamentos de esta experiencia se presentan en el artículo "Del Maestro al Educador Profesional. Bases para la profesionalización”, en este mismo Dossier. 
4) Por disposiciones nacionales, la formación inicial de los profesores tiene una duración de cuatro años. La UCA abrió en 2017 dos carreras: Profesor Universitario de Enseñanza Inicial y Profesor Universitario de Enseñanza Primaria, cohorte que se graduó en 2020 .

5) Estos postulados se explicitan en el punto denominado "El desarrollo de la profesionalidad" .

6) Portfolio de reflexión metacognitiva sobre evidencias de desempeño profesional durante la formación inicial en formato digital.

7) Los Desempeños de Comprensión (Perkins, 1999) son las actividades que permiten a los estudiantes construir sus aprendizajes profundos. Les exigen ir más allá de la información y la memoria creando algo nuevo, reconfigurando, expandiendo y aplicando lo que ya saben, así como extrapolando y construyendo nuevos saberes e intervenciones a partir de esos conocimientos. Este concepto se explicita en el punto "Una innovación disruptiva”.

8) Estas cinco aptitudes (abilities) están definidas en la propuesta del Alverno College (Cf. www. alverno.edu).

9) Este es un eje de especial interés del modelo AIE. Por eso, en estas carreras el peso de ese programa quintuplica el de la Universidad en su conjunto.

10) El horario de actividades es amplio dado que las carreras de grado (Profesorados para el Nivel Primario y para el Nivel Inicial) tienen clase los días de semana (excepto el miércoles) de 2:15 p. m. a 6:00 p. m. Pero las carreras de nivel superior (especializaciones y futuras maestrías) y la licenciatura en Educación Inclusiva y Efectiva desarrollan actividades entre las 6:00 p. m. y las 9:00 p. m.

11) Tanto la viabilidad como la factibilidad de un modelo de intervención y su gestión estratégica se construyen. Para eso se deben combinar tres campos de viabilidad: el de querer hacer (política), el de saber hacer (técnica), y el de poder hacer (administrativo-organizacional) (Aguerrondo, Lugo, Sampedro, 2001).
12) Nirenberg (2012, p. 20) expresa que: "después de extensos debates teóricos es muy difícil atribuir resultados a una sola intervención (...) dada la diversidad de factores que inciden se suele hablar de 'contribución' más que de 'atribución', ante la complejidad, multidimensionalidad y multicausalidad de los fenómenos sociales, particularmente los educativos".

13) Las unidades curriculares presentan un enfoque disciplinar o bien están organizadas en torno a núcleos de problematización o temas de interés en los que convergen diferentes disciplinas que permiten integrar perspectivas, focalizar en cuestiones relevantes y orientar la reflexión crítica y el juicio profesional como base para la toma de decisiones pedagógicas (UCA, 2015, p. 8).

14) Se discuten temáticas como los problemas de la globalización, el impacto del Big Data, las posturas sobre el calentamiento global, qué son los unicornios o las start-up y qué papel juegan, etc. Ver desempeños de estudiantes (2019) en el enlace https://youtu.be/-kKmEvtA-rM

15) Acceder al enlace https://cedoc.infd.edu.ar/ wp-content/uploads/2019/12/Politicas-para-mejorar-las-trayectorias-estudiantiles-en-la-formacion-docente.pdf

16) En 2020 se completó la primera cohorte de $1^{\circ}$ a $4^{\circ}$ año. En términos generales, el plantel de alumnos se estructura con 47 estudiantes en promedio por año, y los estudiantes de primaria casi duplican los de inicial. La estructura organizativa está proyectada para 400 alumnos.

17) Estudiantes de bajo nivel socioeconómico.

18) El lector interesado puede consultar estos tres libros de la Biblioteca de Formación Docente Inicial UCA-Editorial Kapelusz: Aguerrondo \& Gómez, Caride, 2019; Azar, 2020; Aguerrondo y Sampedro, 2020. 